\title{
Neighbourhood deprivation and the Big Five personality traits: associations with adolescent problem behaviour and educational attainment
}

\author{
Jaap Nieuwenhuis ${ }^{1,5}$ (D) Tom Kleinepier ${ }^{2} \cdot$ Heleen Janssen ${ }^{3} \cdot$ Maarten van Ham ${ }^{4,6}$
}

Received: 11 June 2020 / Accepted: 21 June 2021 / Published online: 4 August 2021

(c) The Author(s) 2021

\begin{abstract}
We studied the relation between cumulative exposure to neighbourhood deprivation and adolescents' Big Five personality traits, and the moderating role of personality in the relation between neighbourhood deprivation and the development of problem behaviour and educational attainment. We studied 5365 British adolescents from ages 10 to 16, with neighbourhood information from birth onwards. Extraversion, agreeableness, emotional stability, and openness to experience moderated the relation between deprivation and problem behaviour. For educational attainment, only extraversion was a moderator. This means that higher values on personality traits were related to weaker relations between neighbourhood deprivation and problem behaviour and educational attainment. The results showed the importance of taking into account adolescents' personality when assessing developmental outcomes in relation to neighbourhood deprivation.
\end{abstract}

Keywords Neighbourhood deprivation $\cdot$ Big five personality traits $\cdot$ Educational attainment $\cdot$ Problem behaviour $\cdot$ ALSPAC

Jaap Nieuwenhuis

j.g.nieuwenhuis@ rug.nl

Tom Kleinepier

tom.kleinepier@abf.nl

Heleen Janssen

h.janssen@csl.mpg.de

Maarten van Ham

m.vanham@tudelft.nl

1 Department of Sociology, Zhejiang University, 866 Yuhangtang Road, Hangzhou 310058, China

2 ABF Research, Delft, The Netherlands

3 Independent research group Space, Contexts, and Crime, Max Planck Institute for the Study of Crime, Security and Law, Freiburg, Germany

4 School of Geography and Sustainable Development, University of St. Andrews, St. Andrews, Scotland

5 Department of Sociology, University of Groningen, Groningen, The Netherlands

6 Department of Urbanism, Delft University of Technology, Delft, The Netherlands 


\section{Introduction}

The socio-economic status of the neighbours living in the area surrounding the home in which adolescents grew up is often found to be related to developmental outcomes such as problem behaviour (Leventhal et al., 2009; Nieuwenhuis et al., 2017a; Xue et al., 2005; Yu et al., 2016) and educational attainment (Chetty et al., 2016; Dietz, 2002; Jencks \& Mayer, 1990; Nieuwenhuis \& Hooimeijer, 2016; Nieuwenhuis et al., 2013). The residential neighbourhood may be related to adolescents' problem behaviour and educational attainment through social learning and role model mechanisms (Ainsworth, 2002; Akers et al., 1979). Based on such reasoning, policy responses were to create more socio-economically mixed neighbourhoods, assuming that that poor families could benefit from the presence of, and interaction with more affluent families (Galster \& Friedrichs, 2015). Indeed, children are influenced by their social environment, however, within the same neighbourhood, different adolescents can show different developmental trajectories, suggesting that individual characteristics influence how people respond to growing up in certain environments. Many studies show weak evidence for neighbourhood effects (Nieuwenhuis, 2016), which may be caused by not taking into account individual differences. When only a sub-sample of a population is affected by their neighbourhood surroundings, the sub-sample that is not affected may suppress the results when studying the whole population, causing the weak evidence for neighbourhood effects. Taking into account differences between people within neighbourhoods is crucial to understand what kind of effect a neighbourhood may have on its residents, because a generalised finding for the whole neighbourhood population may not do justice to the different experiences neighbourhood residents may have.

Personality is such an individual characteristic that is often overlooked in neighbourhood effects studies in general, and in neighbourhood effects studies on problem behaviour and educational attainment specifically. Personality has been shown to moderate the relation between neighbourhood characteristics and problem behaviour and educational outcomes (see e.g., Lynam et al., 2000; Meier et al., 2008; Nieuwenhuis et al., 2015, 2017b; Zimmerman, 2010). Personality has been argued to contribute to adolescents' ability to cope with stressful (neighbourhood) environments and with adolescents' malleability (Belsky \& Pluess, 2009; Magnusson \& Stattin, 2006). Therefore, personality traits can be an important moderator between neighbourhood disadvantage and problem behaviour and educational outcomes.

Besides personality being a moderator for neighbourhood effects, personality has also been found to be related to neighbourhood disadvantage, that is, where people with certain personality traits live is potentially not random. A substantial body of literature has demonstrated variations in individual personality between nations and between regions within nations (for a review, see Rentfrow et al., 2008), however, only more recently studies have linked personality to area of residence. For example, residential moving behaviour within and between US states was linked to personality traits (Jokela, 2009; McCann, 2015), and personality traits were also found to cluster spatially across US states and British regions (Rentfrow et al., 2008, 2015) and neighbourhoods in the London metropolitan area (Jokela et al., 2015). There are two reasons why personality may be associated with area of residence. First, self-selection into neighbourhoods based on personality may drive certain levels of clustering. Personality traits may be associated with certain (residential) preferences, which translate into choices for certain neighbourhoods. And second, environments may shape individuals' personality, that is, there may be a contextual effect on personality. Because we investigate outcomes for adolescents, self-selection into neighbourhoods 
is unlikely. Parents usually make the decision where to live, rather than adolescents. However, because personality is partly heritable (Power \& Pluess, 2015), people with certain personality traits may be born into neighbourhoods because their parents sorted into these neighbourhoods due to their personality traits. This constitutes an intergenerational selection effect.

Our study had two core aims. First, exposure to neighbourhood deprivation may not be random amongst adolescents with different personality traits. When studying interactions between personality and neighbourhood deprivation this could lead to wrong interpretations of the interaction term (Vogel \& van Ham, 2018). Therefore, we first examined how cumulative exposure to neighbourhood deprivation during childhood was related to adolescents' personality, using the Big Five model of personality traits. Second, we examined to what extent personality traits played a moderating role in the relation between exposure to neighbourhood deprivation in childhood and the subsequent problem behaviour and educational attainment in adolescence. The Big Five personality traits are a well-established and often used measures in studies of individual personality differences (Goldberg, 1992), and include five broad dimensions to describe individuals' personality: openness to experience, conscientiousness, extraversion, agreeableness, and emotional stability (or the inverse neuroticism). Furthermore, rather than assessing exposure to neighbourhood deprivation at a single point in time, we took into account cumulative exposure to neighbourhood deprivation from birth to adolescence, providing a much more accurate measure of residential disadvantage.

\subsection{Neighbourhoods shaping personality traits}

There are two reason why personality traits may cluster within neighbourhoods, first, neighbourhoods may affect how personality traits develop, and second, personality traits may relate to why people choose to live in certain neighbourhoods. Although personality is regarded as relatively stable (McCrae \& Costa, 2003), through processes of socialisation it is possible that neighbourhoods shape residents' personality traits. When certain norms, attitudes, and behaviours (e.g., deviant attitudes and activities) are prevalent in neighbourhoods, adolescents may acquire these norms and behaviours through peer affiliation. When these norms, attitudes, and behaviours are linked to personality traits, personality traits may be affected when they correspond with the affected norms, attitudes, and behaviours. Another process through which neighbourhoods might influence adolescents' behaviour is social control. In neighbourhoods with higher levels of social control, adults are generally more willing and likely to monitor and correct misbehaving children who are not their own (Wilson, 1987). Through social control residents may also try to enforce certain behaviours, by encouraging some and sanctioning others. When these behaviours are linked to personality traits, people's personality traits, along with their behaviours, may be influenced and changed in the same way (Galster, 2011; Hofstede, 2001).

Neighbourhoods can potentially shape personality in several ways, for example, the Big Five traits extraversion and agreeableness have been linked to community involvement (Ozer \& Benet-Martinez, 2006; Roberts et al., 2007), leading to the expectation that neighbourhoods with high levels of community and social cohesion can promote behaviours related to extraversion and agreeableness. High levels of social cohesion are more often observed in advantaged neighbourhoods (Sampson et al., 1997), predicting a negative relation between neighbourhood disadvantage and extraversion and agreeableness. Another example is that criminal behaviour is negatively related to agreeableness, 
conscientiousness, and emotional stability (Ozer \& Benet-Martinez, 2006; Roberts et al., 2007). Criminality is more often observed in disadvantaged neighbourhoods (Wikström \& Sampson, 2003). Therefore, due to lower levels of social control and more deviant peer group affiliation, neighbourhood disadvantage may be related to lower levels of agreeableness, conscientiousness, and emotional stability. Finally, openness to experience is related the preference for creative and intellectual professions (Ozer \& Benet-Martinez, 2006), which are more often found in more advantaged neighbourhoods (Florida, 2002). People may move into these neighbourhoods in search of likeminded neighbours, or be influenced by their neighbours to become more like them. Therefore, we expect neighbourhood disadvantage to be negatively related to openness to experience.

To summarise, personality traits are related to certain behaviours. When certain behaviours are more prevalent in certain neighbourhoods, adolescents in these neighbourhoods may adopt these behaviours, therewith also affecting the development of the personality traits that are associated with the behaviours. Therefore, we expect that individuals who were exposed to neighbourhood disadvantage for a longer period of time score lower on all Big Five dimensions.

\subsection{Person-environment interactions}

Personality has been found to be a predictor of problem behaviour (Ehrler et al., 1999; Miller \& Lynam, 2001) and educational attainment (De Raad \& Schouwenburg, 1996), although this relation was found to be bidirectional, with problem behaviour also impacting on personality (Klimstra et al., 2010). For our research purposes, however, we employ personality as a moderator between environments (e.g., neighbourhoods) and individual outcomes. The idea is that individuals' inhibitions serve as a moderator for how they deal with environmental stressors: some are more resilient while others are more vulnerable. How people respond to and cope with certain situations depends on individual characteristics such as personality or self-control (Belsky \& Pluess, 2009; Magnusson \& Stattin, 2006; Moffitt et al., 2011). Variations in susceptibility are a useful tool to examine how individuals respond differently to different environments, which is paramount for understanding why certain environments have such detrimental effects on some adolescents, but not on others.

Person-environment interactions involving personality have been studied extensively in studies of family environmental effects (Meeus et al., 2011). For example, personality was found to moderate the association between parental rejection and depression and aggression (Akse et al., 2004). More recently, a few studies have also looked into interactions between neighbourhood environments and personality. Examples include personality traits moderating the relation between neighbourhoods' population structure, physical environment, and social indicators and life satisfaction (Jokela et al., 2015), personality types moderating the relation between neighbourhood disadvantage and educational attainment (Nieuwenhuis et al., 2015) and work commitment and unemployment (Nieuwenhuis et al., 2016), and between neighbourhood immigrant proportion and educational commitments (Nieuwenhuis et al., 2017b), and impulsivity interacting with neighbourhood disadvantage when predicting delinquency (Lynam et al., 2000; Meier et al., 2008; Zimmerman, 2010).

Probably the most obvious personality trait when studying individual resilience is emotional stability: higher levels of emotional stability are related to better coping, and the inverse, neuroticism, is related to poorer coping (Ozer \& Benet-Martinez, 2006; Roberts et al., 2007). People with higher levels of emotional stability are less irritable and tense 
(Goldberg, 1992), and therefore perhaps also more flexible in responding to environmental stressors. Previous research suggests that living in a deprived neighbourhood can be stressful, for example because of poor housing quality, greater crime rates, population density, high-traffic volume streets, and higher levels of noise within one's local surroundings (Evans, 2003). Thus, we expect that higher emotional stability is related to better coping with neighbourhood disadvantage, therefore predicting weaker neighbourhood effects for adolescents with higher emotional stability compared to more neurotic adolescents.

In addition to emotional stability, higher levels on the other Big Five personality traits may also be associated with better coping with disadvantaged neighbourhoods (O'Brien \& DeLongis, 1996), although the patterns here are less straightforward. Higher levels of extraversion are associated with more sociable, energetic, and enthusiastic traits; people with higher levels of agreeableness are more forgiving, warm, and sympathetic; and more conscientious people are more efficient and organised, and less impulsive and careless (Goldberg, 1992). These traits of extraversion, agreeableness, and conscientiousness suggest that adolescents with higher levels on those traits will be better able to deal with negative impulses coming from growing up with neighbourhood disadvantage. People with high levels of openness to experience are more creative, have more liberal values, and can better adapt to change (LePine et al., 2000; Ozer \& Benet-Martinez, 2006; Rentfrow et al., 2008). It is possible that because they are more open to experiences and therefore have more diverse experiences, that they are more flexible in dealing with exposure to negative neighbourhood stressors. Having higher values on any of the five personality traits seems to serve as a buffering role and to contribute to more effective coping with neighbourhood disadvantage.

\subsection{The current study}

Because studies of contextual effects generally ignore individual differences in personality, in this study, we linked personality to neighbourhoods in two ways. First, controlling for individual background characteristics, we studied whether the adolescents' Big Five personality traits were related to levels of neighbourhood deprivation. And second, to examine how adolescents' personality traits related to how they responded to cumulative exposure to neighbourhood deprivation, we studied the person-environment interaction between cumulative exposure to neighbourhood deprivation and personality traits in predicting the development of problem behaviour and educational attainment.

Furthermore, we specifically take into account school poverty. Both neighbourhoods and schools are theorised as contexts in which adolescents spend their time with peers and which influence their problem behaviour and educational attainment (Gaias et al., 2018; Nieuwenhuis, 2018; Nieuwenhuis \& Hooimeijer, 2016; Sykes \& Musterd, 2010). However, peer networks in neighbourhoods and school can overlap when children from the same neighbourhoods go to the same schools (Nieuwenhuis \& Xu, 2021). Not taking into account school poverty could lead to a wrong estimation for neighbourhood disadvantage.

We have the following expectations: (1) longer exposure to neighbourhood disadvantage will be associated with lower values on emotional stability, extraversion, agreeableness, conscientiousness and openness to experience; (2) longer exposure to neighbourhood disadvantage will be associated with more problem behaviour and lower educational attainment; and (3) the association between longer exposure to neighbourhood disadvantage and problem behaviour and educational attainment will be weaker for individuals with higher 
values on emotional stability, extraversion, agreeableness, conscientiousness and openness to experience.

\section{Data and methods}

\subsection{Participants}

We used the Avon Longitudinal Study of Parents and Children (ALSPAC), an ongoing population based cohort study that recruited 14,541 pregnant women living in the county of Avon, UK, and who were expected to give birth between April 1st, 1991 and December 31st, 1992. There was an additional enrolment of 713 children. The total sample consisted of 15,458 fetuses, of which 14,701 were alive at age 1 (Boyd et al., 2013; Fraser et al., 2013). We ran several analyses in this paper on different samples. First, when studying personality, our samples ranged from 5363 to 5365 youth (50.92\% female), whose personality traits were measured when they were 13 years and 6 months old. Second, the study on problem behaviour was based on 4,668 youth (52.04\% female), whose problem behaviour was assessed three times by their parents, when they were 10 years and 8 months, 13 years and 10 months, and 15 years and 6 months old. The average number of observations per respondent was 2.3. The total observations for these analyses were 10,960. Finally, educational attainment was based on 4218 youth (51.45\% female), whose math scores were assessed by standardised Key Stage tests 3 and 4 at ages around 13/14 and 15/16, respectively. The average number of observations per respondent was 1.6. The total observations for these analyses were 6,787. Please note that the study website contains details of all the data that is available through a fully searchable data dictionary at $<$ http://www.bris.ac.uk/ alspac/researchers/data-access/data-dictionary/>.

\subsection{Time-varying variables}

Problem behaviour. The Development and Well-being Assessment (DAWBA) was used to assess problem behaviour (Goodman et al., 2000). Youth's externalising problem behaviour was assessed three times by the youth's parents: at 10 years and 8 months, 13 years and 10 months, and 15 years and 6 months old. Problem behaviour was measured as a scale, constructed from 7 items with 3 answering categories: "No"; "Perhaps"; "Definitely". The items were: "In the last 12 months, the child:" (1) Told lies to get things/favours from others/to get out of things supposed to do; (2) Often started fights other than with brothers \& sisters; (3) Bullied/threatened people; (4) Stayed out much later than supposed to; (5) Has stolen things from house/other people's houses/shops/school; (6) Has run away from home/ ever stayed away all night with respondents permission; and (7) Played truant (bunked off) from school. The items were transformed into three scales ranging from 0 to 2 , one for each moment of data collection. Cronbach's alphas for the scales were: 0.59 (age 10), 0.69 (age 13), and 0.69 (age 15). For descriptive statistics of this and other variables see Appendix.

Educational attainment. To measure educational attainment, we used math scores on the Key Stage 3 and 4 tests (at ages 13/14 and 15/16, respectively). These were linked in through the National Pupil Database (NPD). The ranges of these test scores were different, therefore we transformed the scores to comparable measures. Standardisation of outcome measures over time leads to the problem that mean-level differences over time can be misinterpreted as individual differences over time (Moeller, 2015). Mean-level 
differences over time can arise when, for example, Key Stage tests 3 and 4 are in some way different, leading to mean-level differences in the overall tests scores of the sample, or because of different ages at the time of the tests, the youth may have different interests, resulting in better or worse test scores. Therefore, we used the proportion of maximum scaling (POMS; Little, 2013), which transformed both test scores into a measure ranging from the minimal possible (0) to the maximal possible (1) by using the formula: POMS $=($ observed - minimum $) /($ maximum-minimum $)$. This way, the measure captures the relative rank-order of each individual, instead of mean-level changes.

Neighbourhood deprivation. To measure exposure to neighbourhood deprivation, we linked in Indices of Multiple Deprivation (IMD) for the neighbourhoods in which the youth lived every year of their life (on July, 1st). IMD is build up from the following characteristics: income; employment; health and disability; education, skills and training; barriers to housing and services; living environment; and crime. Neighbourhood deprivation was measured as the years of exposure to neighbourhoods within the 10th (most deprived) decile of the IMD, up until all moments that the dependent variables were assessed. This measure was standardised. We use a cumulative measure of exposure to neighbourhood disadvantage during childhood to eliminate the random noise and/or transitory fluctuations found in single point-in-time measures of neighbourhood deprivation (see Kleinepier \& van Ham, 2017).

Proportion eligible for school meals. As a proxy for school poverty, the proportion of children eligible for school meals was assessed for the school they attended when taking the Key Stage tests (Key Stage 2 around age 10/11; Key stage 3 around age 13/14; Key Stage 4 around age 15/16). For inclusion in the analyses of problem behaviour, all three Key Stages were used; for educational attainment only 3 and 4 were used. These data were linked to ALSPAC from the Annual School Census (ASC). This measure was standardised.

\subsection{Time-invariant variables}

Personality traits. The Big Five personality traits were measured at age 13 years and 6 months, using the International Personality Item Pool (IPIP; Goldberg, 1999), a scale that contains 50 items and comprised of the following personality traits: extraversion, agreeableness, conscientiousness, emotional stability, and openness to experience. Youth were asked to answer how well a statement described them, with five answering categories ranging from "Very like me" to "Not at all like me". Cronbach's alphas for the five scales were: extraversion: 0.84 , agreeableness: 0.72 , conscientiousness: 0.75 , emotional stability: 0.79 , and openness to experience: 0.75 .

Control variables. We included four control variables: parental education, sex, race, and mother's age at delivery. (1) Parental education was measured as the average of the highest achieved education of the mother and of the partner, as assessed at 32 weeks into gestation. Education consisted of five categories: (1) Certificate of Secondary Education (CSE) or General Certificate of Secondary Education (GCSE) levels D, E, F, or G; (2) vocational; (3) Ordinary Level (O Level) or GCSE levels A, B, or C; (4) Advanced Level (A Level); and (5) university degree. (2) Sex was included in the models as a female $=1$ and male $=0.3$ ) Race was measured as non-white $=1$ and white $=0$.

4) Mother's age at delivery was measured as age at delivery in years, ranging from 16 to 43 . 


\subsection{Analyses}

To study how exposure to neighbourhood deprivation and personality traits were related, we performed several sets of analyses. First, we fitted five cross-sectional multilevel regression models, predicting the five personality traits at age 13 with years of exposure to neighbourhood poverty, starting with the neighbourhood at birth. Individuals were nested into neighbourhood decile of deprivation at age 13 (using the IMD deciles). Second, we regressed problem behaviour on exposure to neighbourhood deprivation, controlled for, amongst others, personality traits. We used a multilevel random-effects regression model, with time, nested in individuals, nested in IMD deciles at age 13. To test whether personality traits interacted with exposure to neighbourhood deprivation, we ran a model with cross-level interactions for each personality trait. Third, we regressed educational attainment on exposure to neighbourhood deprivation, controlled for, amongst others, personality traits. We used a multilevel random-effects regression model, with time nested in individuals, nested in IMD deciles at age 13. Again, to test whether personality traits interacted with exposure to neighbourhood deprivation, we ran a model with cross-level interactions for each personality trait. We drew interaction plots for all significant interactions. The models were estimated using MlwiN 2.35 through Stata 14.1 using the user written runmlwin command (Leckie \& Charlton, 2013).

\section{Results}

The pairwise correlations for the five personality traits (Table 1) show negative relations between the duration of exposure to neighbourhood deprivation (i.e., the highest IMD decile) and extraversion and emotional stability. The IMD decile at age 13 was negatively correlated with agreeableness, emotional stability, and openness to experience. The level of problem behaviour was positively correlated and math results were negatively correlated with both neighbourhood IMD decile at age 13 and exposure to neighbourhood deprivation.

Table 2 shows the regression models predicting personality traits. All models have significant goodness of fit compared to the baseline model. Only emotional stability was negatively related to exposure to neighbourhood poverty, however, the coefficient is very small, making this relation almost negligible. Extraversion and openness to experience were close to having a significant relation with exposure to neighbourhood poverty ( $p=0.053$ and $p=0.059$, respectively), however, because the relation was comparably small, these results can possibly also be classified as negligible. Although Table 1 showed some correlations between IMD decile and the personality traits, the zero variance on the neighbourhood level in Table 2 emphasised that personality may not be that strongly related to neighbourhood deprivation. Of the other variables, especially sex had a relatively strong relation with all five personality traits, with girls being more extravert and agreeable, but lower on conscientiousness, emotional stability, and openness to experience.

Tables 3 and 4 show the models predicting problem behaviour and educational attainment, respectively. Both models have significant goodness of fit. Exposure to neighbourhood deprivation was positively related to problem behaviour, and negatively to educational attainment. Higher levels of extraversion were related to more problem behaviour whereas higher levels of agreeableness, conscientiousness, and emotional stability were 


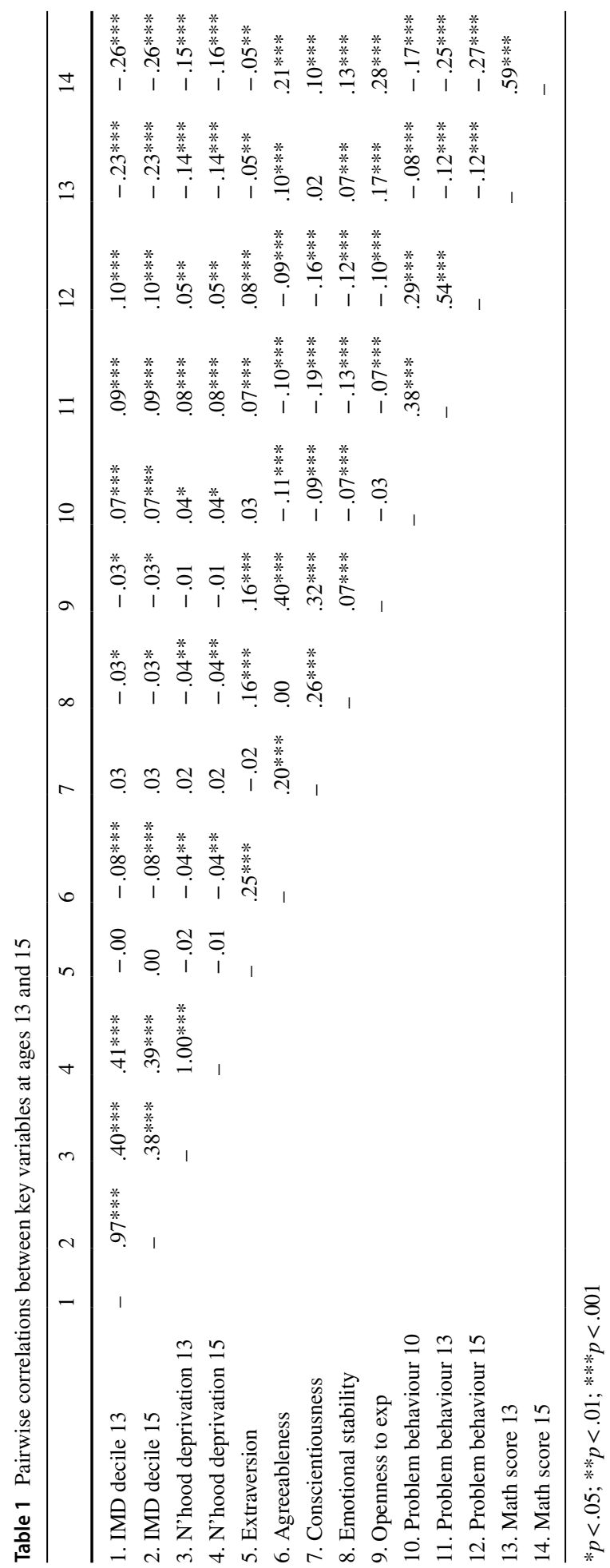




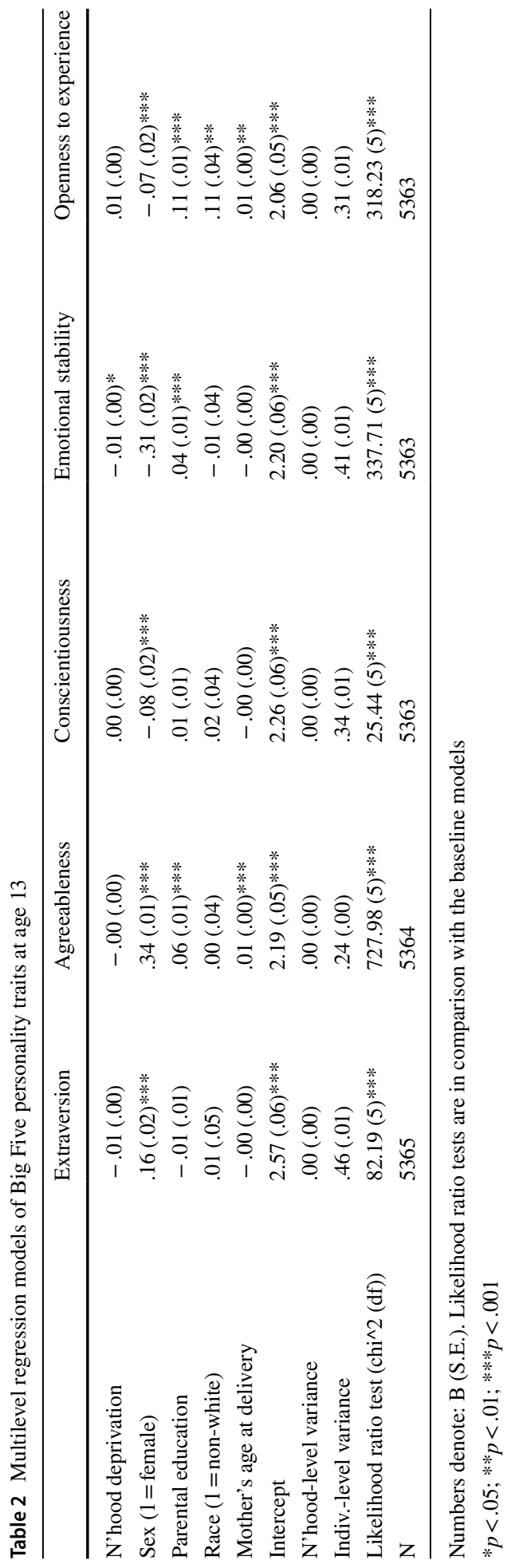


Table 3 Multilevel random-effects regression of problem behaviour $(\mathrm{N}=10,960)$

\begin{tabular}{lll}
\hline & Model 1 B (S.E.) & Model 2 B (S.E.) \\
\hline Time-varying variables & & \\
Neighbourhood deprivation & $.01(.00)^{* * *}$ & $.04(.01)^{* * *}$ \\
Proportion eligible for school meals & $.00(.00)$ & $-.00(.00)$ \\
Time-invariant variables & & \\
Extraversion & $.02(.00)^{* * *}$ & $.02(.00)^{* * *}$ \\
Agreeableness & $-.02(.00)^{* * *}$ & $-.03(.00)^{* * *}$ \\
Conscientiousness & $-.03(.00)^{* * *}$ & $-.03(.00)^{* * *}$ \\
Emotional stability & $-.03(.00)^{* * *}$ & $-.03(.00)^{* * *}$ \\
Openness to experience & $-.00(.00)$ & $-.00(.00)$ \\
Sex (1=female) & $-.02(.00)^{* * *}$ & $-.02(.00)^{* * *}$ \\
Parental education & $-.01(.00)^{* *}$ & $-.01(.00)^{* *}$ \\
Race (1=non- white) & $.00(.01)$ & $.01(.01)$ \\
Mother's age at delivery & $-.00(.00)^{* *}$ & $-.00(.00)^{*}$ \\
Cross-level interactions: neighbourhood deprivation & with & \\
Extraversion & & $-.01(.00)^{* *}$ \\
Agreeableness & & $-.01(.01)^{*}$ \\
Conscientiousness & & $-.00(.01)$ \\
Emotional stability & & $-.01(.00)^{* *}$ \\
Openness to experience & & $-.01(.01)^{*}$ \\
Intercept & $.16(.01)^{* * *}$ & $.17(.01)^{* * *}$ \\
Neighbourhood-level variance & $.00(.00)$ & $.00(.00)$ \\
Individual-level variance & $.01(.00)^{* * *}$ & $.01(.00)^{* * *}$ \\
Time-level variance & $.02(.00)^{* * *}$ & $.02(.00)^{* * *}$ \\
Likelihood ratio test (chi^2 (df)) & $358.53(11)^{* * *}$ & $50.06(5)^{* * *}$ \\
\hline
\end{tabular}

The likelihood ratio test for Model 1 is in comparison with the baseline model. Model 2 is in comparison with Model 1

$* p<.05 ; * * p<.01 ; * * * p<.001$

related to less problem behaviour. Openness to experience was not related to problem behaviour. Higher levels of extraversion and conscientiousness were related to lower educational attainment, whereas higher levels of agreeableness, emotional stability, and openness to experience were related to higher educational attainment. The proportion of students who were eligible for school meals, as indicator of poverty in the school, was negatively related to educational attainment.

The cross-level interactions between exposure to neighbourhood deprivation and the personality traits (Model 2 in Tables 3 and 4) show that all Big Five personality traits, but conscientiousness, moderate the effect of exposure to neighbourhood poverty on problem behaviour, that is, the positive relation between neighbourhood poverty and problem behaviour was weaker for adolescents with higher extraversion, agreeableness, emotional stability, and openness to experience. This models has a significant goodness of fit. All interaction plots (Fig. 1) show the same pattern, that is, a horizontal line for adolescents who had high levels on the personality traits (i.e., simple slope analyses show no differences in problem behaviour based on the length of exposure to neighbourhood deprivation; 
Table 4 Multilevel random-effects regression of educational attainment $(\mathrm{N}=6783)$

\begin{tabular}{|c|c|c|}
\hline & Model 1 B (S.E.) & Model 2 B (S.E.) \\
\hline \multicolumn{3}{|l|}{ Time-varying variables } \\
\hline Neighbourhood deprivation & $-.01(.00)^{*}$ & $-.01(.00)^{* *}$ \\
\hline Proportion eligible for school meals & $-.03(.00)^{* * *}$ & $-.03(.00)^{* * *}$ \\
\hline \multicolumn{3}{|l|}{ Time-invariant variables } \\
\hline Extraversion & $-.02(.00)^{* * *}$ & $-.02(.00)^{* * *}$ \\
\hline Agreeableness & $.02(.00)^{* * *}$ & $.02(.00) * * *$ \\
\hline Conscientiousness & $-.01(.00)^{*}$ & $-.01(.00)^{*}$ \\
\hline Emotional stability & $.02(.00)^{* * * *}$ & $.02(.00)^{* * * *}$ \\
\hline Openness to experience & $.04(.00)^{* * *}$ & $.04(.00)^{* * *}$ \\
\hline $\operatorname{Sex}(1=$ female $)$ & $-.00(.00)$ & $-.00(.00)$ \\
\hline Parental education & $.03(.00)^{* * *}$ & $.03(.00)^{* * *}$ \\
\hline Race (1=non-white) & $-.01(.01)$ & $-.01(.01)$ \\
\hline Mother's age at delivery & $.00(.00)$ & $.00(.00)$ \\
\hline \multicolumn{3}{|c|}{ Cross-level interactions: neighbourhood deprivation with } \\
\hline Extraversion & & $.01(.00)^{*}$ \\
\hline Agreeableness & & $.01(.00)$ \\
\hline Conscientiousness & & $.00(.00)$ \\
\hline Emotional stability & & $.00(.00)$ \\
\hline Openness to experience & & $-.00(.00)$ \\
\hline Intercept & $.44(.01)^{* * *}$ & $.44(.01)^{* * *}$ \\
\hline Neighbourhood-level variance & $.00(.00)$ & $.00(.00)$ \\
\hline Individual-level variance & $.01(.00)^{* * *}$ & $.01(.00)^{* * *}$ \\
\hline Time-level variance & $.01(.00)^{* * *}$ & $.01(.00)^{* * *}$ \\
\hline Likelihood ratio test $\left(\mathrm{chi}^{\wedge} 2(\mathrm{df})\right)$ & $774.02(11)^{* * *}$ & $11.06(5)$ \\
\hline
\end{tabular}

The likelihood ratio test for Model 1 is in comparison with the baseline model. Model 2 is in comparison with Model 1

${ }^{*} p<.05 ; * * p<.01 ; * * * p<.001$

extraversion: $\mathrm{b}=0.009 ; p=0.315$; agreeableness: $\mathrm{b}=0.010 ; p=0.324$; emotional stability: $\mathrm{b}=0.013 ; p=0.163$; and openness to experience: $\mathrm{b}=-0.010 ; p=0.381$ ), and a positive slope for adolescents with low levels on the five personality traits (i.e., higher levels of problem behaviour with longer exposure to neighbourhood deprivation; extraversion: $\mathrm{b}=0.064 ; p<0.001$; agreeableness: $\mathrm{b}=0.063 ; p<0.001$; emotional stability: $\mathrm{b}=0.060$; $p<0.001$; and openness to experience: $\mathrm{b}=0.057 ; p<0.001)$. Adolescents with no exposure to neighbourhood deprivation showed the same levels of problem behaviour, independent of their personality traits. The differences became pronounced for adolescents with high levels of exposure to neighbourhood deprivation, there adolescents with low levels of the personality traits had higher levels of problem behaviour.

For educational attainment we found that the negative relation with neighbourhood poverty is weaker for adolescents with higher extraversion, but not for the other traits. When including all five interactions, this models did not have a significant goodness of fit (chi^2 $(\mathrm{df})=11.06(5) ; p=0.050)$, however, rerunning the likelihood ratio test while including 

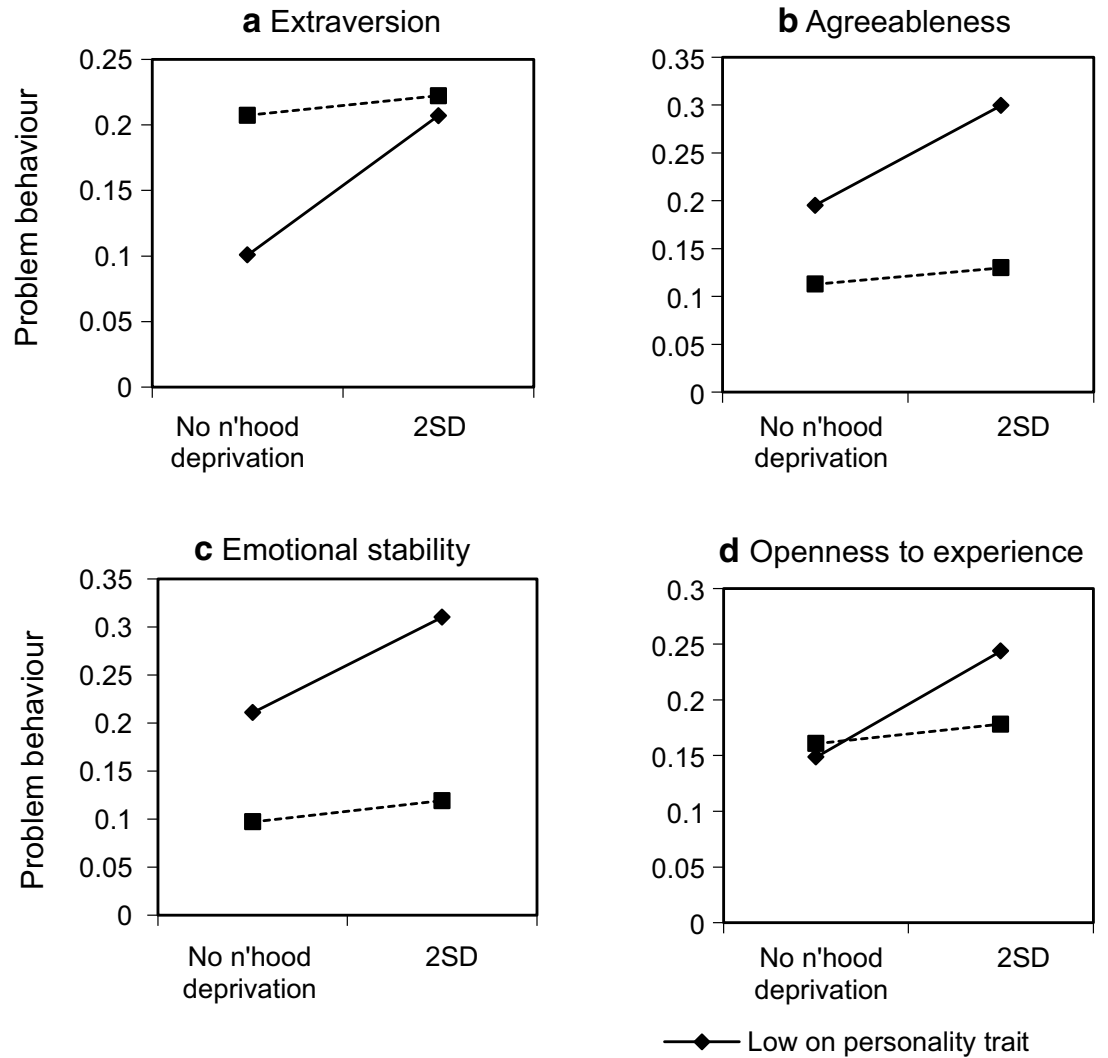

Fig. 1 Interaction plots between exposure to neighbourhood deprivation and personality traits for the problem behaviour model. Note 'Low' and 'high' on personality trait mean the minimum and maximum values on the traits, respectively

Fig. 2 Interaction plot between exposure to neighbourhood deprivation and extraversion for the educational attainment model. Note: 'Low' and 'high' on personality trait mean the minimum and maximum values on the traits, respectively

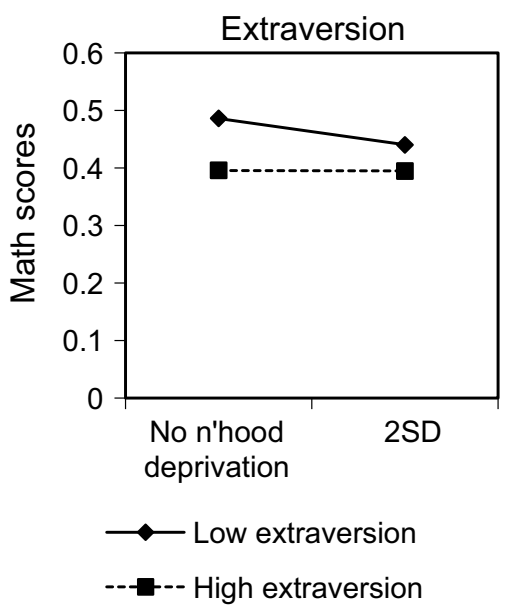


only the interaction with extraversion shows a significant goodness of fit $\left(\mathrm{chi}^{\wedge} 2(\mathrm{df})=5.49\right.$ $(1) ; p=0.019)$. This gives us more confidence in the accuracy of the interaction. The plot of the interaction (Fig. 2) show that the slope for adolescents who had high extraversion $(b=-0.001 ; p=0.919)$ was horizontal, while for adolescents with low levels of extraversion $(b=-0.028 ; p=0.001)$, the slope was negative. This means that especially for adolescents with low extraversion, higher levels of exposure to neighbourhood deprivation was related to lower educational attainment.

\section{Discussion}

We examined how and to what extent cumulative exposure to neighbourhood deprivation during childhood related to the Big Five personality traits (i.e., extraversion, agreeableness, conscientiousness, emotional stability, and openness to experience), and how these personality traits moderate the relation between exposure to neighbourhood deprivation and youth's developmental outcomes (i.e., problem behaviour and educational attainment). Years of exposure to most deprived neighbourhoods was negatively related to extraversion, agreeableness, and emotional stability. However, after controlling for relevant individual characteristics, only the relation with emotional stability remained statistically significant. Whether this relation is caused by adolescents becoming less emotionally stable when faced with neighbourhood deprivation (socialisation effect), or that less emotionally stable people more often live for longer periods in deprived neighbourhoods, and adolescents inherit this trait from their parents (selection effect), is still unclear. Future studies with repeated measures of personality traits could provide further exploration of this relation. However, what is clear, is that the longer adolescents are exposed to neighbourhood deprivation, the lower their emotional stability (or the higher their neuroticism), albeit a weak relation. This finding is in line with other research suggesting neighbourhoods and personality traits are related (e.g., Jokela et al., 2015), and it also highlights the importance of accounting for neighbourhood disadvantage longitudinally.

Next we studied how the five personality traits moderate the relation between exposure to neighbourhood deprivation and problem behaviour and educational attainment. First, studying the main effects, we found that the length of exposure to neighbourhood deprivation was positively related to problem behaviour and negatively related to educational attainment. This is in line with earlier research (see e.g., Jencks \& Mayer, 1990; Leventhal et al., 2009; Nieuwenhuis \& Hooimeijer, 2016). Again, it is difficult to say here whether the exposure to neighbourhood deprivation causes differences in problem behaviour and educational attainment, or whether families selectively move into neighbourhoods with different levels of deprivation, and the family characteristics that cause the choice for certain neighbourhoods also cause problem behaviour and educational attainment. Ideally, future research should take into account the residential histories of parents as well, in order to model potential intergenerational selection effects (see e.g., Sharkey, 2008). However, we specifically control for parental education, and parental education partially explains the type of job parents attain, and therewith also their income. Families' income logically limits the set of neighbourhoods they can choose from. Because in the models, we take parental income into account by proxy through parental education, and because normally adolescents do not choose their own neighbourhoods, we partially control for potential selection bias, therewith strengthening the case for an effect of exposure to neighbourhood deprivation on problem behaviour and educational attainment. 
Second, we examined the interactions between exposure to neighbourhood deprivation and the five personality traits. Because personality traits did not relate to exposure to neighbourhood deprivation (except for the weak relation for emotional stability), we can rule out any bias arising from selective clustering of personality traits into neighbourhoods. It became clear that the positive relation between neighbourhood deprivation and problem behaviour was only present for adolescents who scored low on four the five personality traits (all except conscientiousness). These findings suggest that adolescents with high levels on any of these four personality traits were more resilient, were better able to cope with neighbourhood deprivation, and therefore showed no relation between neighbourhood deprivation and problem behaviour. For the relation between neighbourhood deprivation and educational attainment, we only found moderation effects for extraversion. Again, this suggests that adolescent with higher levels of extraversion were better able to cope with growing up with deprivation and their relation between neighbourhood deprivation and educational attainment was much weaker or absent compared to adolescents with lower levels of extraversion.

The results of the moderation models emphasised the importance of person-environment interactions when studying contextual effects (Belsky \& Pluess, 2009; Magnusson $\&$ Stattin, 2006). When not growing up with neighbourhood deprivation, most youth have similar developmental patterns, however, when growing up in deprived neighbourhoods for long periods of time, in line with other studies (e.g. Nieuwenhuis et al., 2015), some youth show more resilience, while other youth are more vulnerable. This difference in susceptibility is related to stark differences in developmental outcomes such as problem behaviour and educational attainment.

One assumption behind studies of neighbourhood effects on adolescent outcomes is that some sort of social interaction between people takes place. It can be argued that the most relevant group of people adolescents interact with are their peers, whom they can also meet at school. By specifically controlling for school poverty in the models, we tried to overcome this problem. A limitation is that we did not have information about where the schools were located, therefore limiting our ability to speculate about how much overlap there could be between neighbourhood and school populations. Future studies would benefit from having this information, because it can help to understand how much of the neighbourhood effect is moderated through the school (see e.g., Sykes \& Musterd, 2010).

\subsection{Selection bias}

Direct selection bias based on adolescents' personality is unlikely, because adolescents normally do not choose the neighbourhoods they live in. However, their parents do make this decision, and, because parental personality may again be related to the personality of their offspring, there potentially exists a clustering of adolescents' personality traits within different types of neighbourhoods, due to indirect selection via the parents.

People may select neighbourhoods based on certain observed behaviours in those neighbourhoods (such as the perceived presence of people who are, e.g., outgoing, creative, community driven, or family driven), and these behaviours may be related to certain personality traits. Therefore, personality traits and their associated behaviours amongst the residents of a neighbourhood where one potentially wants to move, may be a pull factor for individuals when choosing a neighbourhood to live in. And, in the same sense as personality traits amongst neighbourhood residents can serve as pull factors, they can also serve as push factors. Personality traits and their associated behaviours amongst neighbourhood 
residents can selectively encourage people with certain personality traits to move out of certain neighbourhoods, when their own ideas of normal behaviour do not align with that of other neighbourhood residents.

Furthermore, individual differences in preferences to own or rent a home may steer people into different types of neighbourhoods as well. For example, people higher on agreeableness and lower on conscientiousness have a preference for homeownership over renting (Ben-Shahar \& Golan, 2014). This would result in variation on these traits based on the proportion of owned or rented properties in a neighbourhood. In general, low-income neighbourhoods have a larger share of (social) rented housing than higher-income neighbourhoods (Stephens, 2013). Therefore, selective in- and out-migration of people with certain personality traits can explain differences between neighbourhoods in the prevalence of certain personality traits. However, to reiterate, adolescents do not choose the neighbourhoods they live in. Therefore, a neighbourhood selection effect caused by personality traits may occur only through the parents. By restricting our sample to adolescents, we minimised the chance of personality traits driving a selection bias.

\section{Conclusion}

Many studies assume a generalisability to the whole population when it comes to the relation between exposure to neighbourhood disadvantage and problem behaviour and educational outcomes. However, based on the differences we found between people with different personality traits, this assumption is likely to be misguided. Studies that try to assess neighbourhood effects using whole populations might find much weaker evidence for them, just because the effects get obscured by personality traits. However, when focussing on vulnerable populations (based on their personality traits), effects may become more pronounced. We showed that it is important not to oversimplify neighbourhood effects, especially since it is a field where policy makers base their decisions on when implementing urban regeneration or neighbourhood social mix policies. Oversimplifications of how neighbourhoods are related to individual behaviour and outcomes can lead to ineffective policy. Knowing who is affected how and when can result in more targeted neighbourhood policy.

\section{Appendix}

The following additional tables show the descriptive statistics of the variables used in the models with as dependent variable personality (Table 5), problem behaviour (Table 6), and educational attainment (Table 7). 
Table 5 Descriptive statistics for the variables used in the models of personality $(\mathrm{N}=5365)$
Table 6 Descriptive statistics for the variables used in the models of problem behaviour $(\mathrm{N}=10,960)$
Table 7 Descriptive statistics for the variables used in the models of educational attainment $(\mathrm{N}=6783)$

\begin{tabular}{lllll}
\hline & Mean & SD & Min & Max \\
\hline Extraversion $^{\text {Agreeableness }}{ }^{\mathrm{a}}$ & 2.52 & .68 & 0 & 4 \\
Conscientiousness $^{\mathrm{b}}$ & 2.78 & .52 & 0 & 4 \\
Emotional stability $^{\mathrm{b}}$ & 2.19 & .59 & 0 & 4 \\
Openness to experience $^{\mathrm{b}}$ & 2.16 & .66 & 0 & 4 \\
Neighbourhood deprivation $_{\text {Sex }(1=\text { female) }}$ & .53 & .57 & 0 & 4 \\
Parental education & .51 & .50 & 0 & 1 \\
Race (1=non-white) & 3.29 & 1.14 & 1 & 5 \\
Mother's age at delivery & .04 & .19 & 0 & 1 \\
\hline
\end{tabular}

${ }^{\mathrm{a}} \mathrm{N}=5364 ;{ }^{\mathrm{b}} \mathrm{N}=5363$

\begin{tabular}{lllll}
\hline & Mean & SD & Min & Max \\
\hline Problem behaviour & .08 & .17 & 0 & 2 \\
Extraversion & .52 & .69 & -2 & 2 \\
Agreeableness & .78 & .52 & -2 & 2 \\
Conscientiousness & .20 & .58 & -1.7 & 2 \\
Emotional stability & .17 & .65 & -2 & 2 \\
Openness to experience & .58 & .57 & -1.6 & 2 \\
Neighbourhood deprivation & -.20 & .66 & -.34 & 4.58 \\
Sex $(1=$ female $)$ & .52 & .50 & 0 & 1 \\
Parental education & 3.27 & 1.11 & 1 & 5 \\
Race (1=non-white) & .04 & .18 & 0 & 1 \\
Mother's age at delivery & 29.23 & 4.38 & 16 & 44 \\
Proportion eligible for school meals & -.24 & .78 & -1.07 & 8.48 \\
\hline
\end{tabular}

\begin{tabular}{lllll}
\hline & Mean & SD & Min & Max \\
\hline Educational attainment & .59 & .15 & 0 & 1 \\
Extraversion & .53 & .68 & -2 & 2 \\
Agreeableness & .76 & .52 & -2 & 2 \\
Conscientiousness & .19 & .57 & -1.9 & 2 \\
Emotional stability & .15 & .65 & -2 & 2 \\
Openness to experience & .56 & .56 & -2 & 2 \\
Neighbourhood deprivation & -.14 & .85 & -.34 & 4.74 \\
Sex $(1=$ female $)$ & .52 & .50 & 0 & 1 \\
Parental education & 3.17 & 1.12 & 1 & 5 \\
Race (1=non-white) & .04 & .19 & 0 & 1 \\
Mother's age at delivery & 28.97 & 4.38 & 16 & 44 \\
Proportion eligible for school meals & -.19 & .80 & -1.13 & 9.31 \\
\hline
\end{tabular}


Acknowledgements We are extremely grateful to all the families who took part in this study, the midwives for their help in recruiting them, and the whole ALSPAC team, which includes interviewers, computer and laboratory technicians, clerical workers, research scientists, volunteers, managers, receptionists and nurses. The UK Medical Research Council and Wellcome (Grant ref: 102215/2/13/2) and the University of Bristol provide core support for ALSPAC. This publication is the work of the authors and Jaap Nieuwenhuis, Tom Kleinepier, Heleen Janssen, and Maarten van Ham will serve as guarantors for the contents of this paper. A comprehensive list of grants funding (PDF, 459KB) is available on the ALSPAC website. This research was specifically funded by the European Research Council under the European Union's Seventh Framework Programme (FP/2007-2013) / ERC Grant Agreement n. 615159 (ERC Consolidator Grant DEPRIVEDHOODS, Socio-spatial inequality, deprived neighbourhoods, and neighbourhood effects).

\section{Declarations}

Conflict of interest The authors report no conflict of interests.

Ethical approval Ethical approval for the study was obtained from the ALSPAC Ethics and Law Committee and the Local Research Ethics Committees.

Informed consent Informed consent for the use of data collected via questionnaires and clinics was obtained from participants following the recommendations of the ALSPAC Ethics and Law Committee at the time.

Open Access This article is licensed under a Creative Commons Attribution 4.0 International License, which permits use, sharing, adaptation, distribution and reproduction in any medium or format, as long as you give appropriate credit to the original author(s) and the source, provide a link to the Creative Commons licence, and indicate if changes were made. The images or other third party material in this article are included in the article's Creative Commons licence, unless indicated otherwise in a credit line to the material. If material is not included in the article's Creative Commons licence and your intended use is not permitted by statutory regulation or exceeds the permitted use, you will need to obtain permission directly from the copyright holder. To view a copy of this licence, visit http://creativecommons.org/licenses/by/4.0/.

\section{References}

Ainsworth, J. W. (2002). Why does it take a village? The mediation of neighborhood effects on educational achievement. Social Forces, 81(1), 117-152.

Akers, R. L., Krohn, M. D., Lanza-Kaduce, L., et al. (1979). Social learning and deviant behavior: A specific test of a general theory. American Sociological Review, 44(4), 636-655.

Akse, J., Hale, W. W., III., Engels, R. C. M. E., Raaijmakers, Q. A. W., \& Meeus, W. H. J. (2004). Personality, perceived parental rejection and problem behavior in adolescence. Social Psychiatry and Psychiatric Epidemiology, 39, 980-998.

Belsky, J., \& Pluess, M. (2009). Beyond diathesis stress: Differential susceptibility to environmental influences. Psychological Bulletin, 135(6), 885-908.

Ben-Shahar, D., \& Golan, R. (2014). Real estate and personality. Journal of Behavioral and Experimental Economics, 53, 111-119.

Boyd, A., Golding, J., Macleod, J., Lawlor, D. A., Fraser, A., Henderson, J., Molloy, L., et al. (2013). Cohort profile: The 'children of the 90s' - the index offspring of the Avon longitudinal study of parents and children. International Journal of Epidemiology, 42(1), 111-127.

Chetty, R., Hendren, N., \& Katz, L. F. (2016). The effects of exposure to better neighborhoods on children: New evidence from the moving to opportunity experiment. American Economic Review, 106(4), 855-902.

De Raad, B., \& Schouwenburg, H. C. (1996). Personality in learning and education: A review. European Journal of Personality, 10(5), 303-336.

Dietz, R. D. (2002). The estimation of neighborhood effects in the social sciences: An interdisciplinary approach. Social Science Research, 31, 539-575.

Ehrler, D. J., Evans, J. G., \& McGhee, R. L. (1999). Extending big-five theory into childhood: A preliminary investigation into the relationship between big-five personality traits and behavior problems in children. Psychology in the Schools, 36(6), 451-458. 
Evans, G. W. (2003). The built environment and mental health. Journal of Urban Health, 80(4), 536-555.

Florida, R. (2002). The rise of the creative class. Basic Books.

Fraser, A., Macdonald-Wallis, C., Tilling, K., Boyd, A., Golding, J., Davey Smith, G., Henderson, J., et al. (2013). Cohort profile: The Avon longitudinal study of parents and children: ALSPAC mothers cohort. International Journal of Epidemiology, 42, 97-110.

Gaias, L. M., Lindstrom Johnson, S., White, R. M. B., Pettigrew, J., \& Dumka, L. (2018). Understanding school-neighborhood mesosystemic effects on adolescent development. Adolescent Research Review, $3,301-319$.

Galster, G. C. (2011). The mechanism(s) of neighbourhood effects: Theory, evidence, and policy implications. In M. van Ham, D. Manley, N. Bailey, L. Simpson, \& D. Maclennan (Eds.), Neighbourhood effects research: New perspectives (pp. 23-56). Springer.

Galster, G. C., \& Friedrichs, J. (2015). The dialectic of neighbourhood social mix: Editors' introduction to the special issue. Housing Studies, 30, 175-191.

Goldberg, L. R. (1992). The development of markers for the big-five factor structure. Psychological Assessment, 4, 26-42.

Goldberg, L. R. (1999). A broad-bandwidth, public domain, personality inventory measuring the lower-level facets of several five-factor models. In I. Mervielde, I. Deary, F. De Fruyt, \& F. Ostendorf (Eds.), Personality Psychology in Europe (pp. 7-28). Tilburg University Press.

Goodman, R., Ford, T., Richards, H., Gatward, R., \& Meltzer, H. (2000). The development and well-being assessment: Description and initial validation of an integrated assessment of child and adolescent psychopathology. Journal of Child Psychology and Psychiatry, 41(5), 645-655.

Hofstede, G. (2001). Culture's consequences: Comparing values, behaviors, institutions, and organizations across nations (2nd ed.). Sage.

Jencks, C., \& Mayer, S. E. (1990). The social consequences of growing up in poor neighbourhood. In L. E. Lynn \& M. G. H. McGeary (Eds.), Inner-city poverty in the United States (pp. 111-186). National Academy Press.

Jokela, M. (2009). Personality predicts migration within and between U.S. states. Journal of Research in Personality, 43, 79-83.

Jokela, M., Bleidorm, W., Lamb, M. E., Gosling, S. D., \& Rentfrow, P. J. (2015). Geographically varying associations between personality and life satisfaction in the London metropolitan area. PNAS, 112(3), 725-730.

Kleinepier, T., \& van Ham, M. (2017). The temporal stability of children's neighborhood experiences: A follow-up from birth to age 15. Demographic Research, 36, 1813-1826.

Klimstra, T. A., Akse, J., Hale, W. W., Raaijmakers, Q. A. W., \& Meeus, W. H. J. (2010). Longitudinal associations between personality traits and problem behavior symptoms in adolescence. Journal of Research in Personality, 44(2), 273-284.

Leckie, G., \& Charlton, C. (2013). runmlwin-A program to run the MLwiN multilevel modelling software from within stata. Journal of Statistical Software, 52(11), 1-40.

LePine, J. A., Colquitt, J. A., \& Erez, A. (2000). Adaptability to changing task contexts: Effects of general cognitive ability, conscientiousness, and openness to experience. Personnel Psychology, 53, 563-593.

Leventhal, T., \& Brooks-Gunn, J. (2000). The neighborhoods they live in: The effects of neighborhood residence on child and adolescent outcomes. Psychological Bulletin, 126, 309-337.

Leventhal, T., Dupere, V., \& Brooks-Gunn, J. (2009). Neighborhood influences on adolescent development. In R. M. Lerner \& L. Steinberg (Eds.), Handbook of Adolescent Psychology (pp. 411-443). Hoboken, NJ: Wiley.

Little, T. D. (2013). Longitudinal structural equation modelling. The Guilford Press.

Lynam, D. R., Caspi, A., Moffit, T. E., Wikström, P.-O., Loeber, R., \& Novak, S. (2000). The interaction between impulsivity and neighborhood context on offending: The effects of impulsivity are stronger in poorer neighborhoods. Journal of Abnormal Psychology, 109(4), 563-574.

Magnusson, D., \& Stattin, H. (2006). The person in context: A holistic-interactionistic approach. In R. M. Lerner \& W. Damon (Eds.), Theoretical models of human development (pp. 400-464). Wiley.

McCann, S. J. H. (2015). Big Five personality and residential mobility: A state-level analysis of the USA. Journal of Social Psychology, 155, 274-291.

McCrae, R. R., \& Costa, P. T., Jr. (2003). Personality in adulthood: A Five-Factor Theory perspective (2nd ed.). Guilford.

Meeus, W., van de Schoot, R., Klimstra, T., \& Branje, S. (2011). Personality types in adolescence: Change and stability and links with adjustment and relationships: A five-wave longitudinal study. Developmental Psychology, 47, 1181-1195. 
Meier, M. H., Slutske, W. S., Arndt, S., \& Cadoret, R. J. (2008). Impulsive and callous traits are more strongly associated with delinquent behavior in higher risk neighborhoods among boys and girls. Journal of Abnormal Psychology, 117(2), 377-385.

Miller, J. D., \& Lynam, D. (2001). Structural models of personality and their relation to antisocial behavior: A meta-analytic review. Criminology, 39(4), 765-798.

Moeller, J. (2015). A word on standardization in longitudinal studies: Don't. Frontiers in Psychology, 6, 1389.

Moffitt, T. E., Arsenault, L., Belsky, D., Dickson, N., Hancox, R. J., Harrington, H., Houts, R., et al. (2011). A gradient of childhood self-control predicts health, wealth, and public safety. PNAS, 108(7), 2693-2698.

Nieuwenhuis, J. (2016). Publication bias in the neighbourhood effects literature. Geoforum, 70, 89-92.

Nieuwenhuis, J. (2018). The interaction between school poverty and agreeableness in predicting educational attainment. Personality and Individual Differences, 127, 85-88.

Nieuwenhuis, J., \& Hooimeijer, P. (2016). The association between neighbourhoods and educational achievement, a systematic review and meta-analysis. Journal of Housing and the Built Environment, 31(2), 321-347.

Nieuwenhuis, J., Hooimeijer, P., \& Meeus, W. (2015). Neighbourhood effects on educational attainment of adolescents, buffered by personality and educational commitment. Social Science Research, 50, 100-109.

Nieuwenhuis, J., Hooimeijer, P., van Dorsselaer, S., \& Vollebergh, W. (2013). Neighbourhood effects on school achievement: The mediating effect of parenting and problematic behaviour? Environment and Planning A, 45(9), 2135-2153.

Nieuwenhuis, J., Hooimeijer, P., van Ham, M., \& Meeus, W. (2017b). Neighbourhood effects on migrant and native youth's educational commitments, an enquiry into personality differences. Urban Studies, 54(10), 2285-2304.

Nieuwenhuis, J., van Ham, M., Yu, R., Branje, S., Meeus, W., \& Hooimeijer, P. (2017a). Being poorer than the rest of the neighborhood: Relative deprivation and problem behavior of youth. Journal of Youth and Adolescence, 46(9), 1891-1904.

Nieuwenhuis, J., \& Xu, J. (2021). Residential segregation and unequal access to schools. Social Inclusion, $9(2), 142-153$.

Nieuwenhuis, J., Yu, R., Branje, S., Meeus, W., \& Hooimeijer, P. (2016). Neighbourhood poverty, work commitment and unemployment in early adulthood: a longitudinal study into the moderating effect of personality. PLOS ONE, 11(12), 0167830.

O'Brien, T. B., \& DeLongis, A. (1996). The interactional context of problem-, emotion-, and relationshipfocused coping: The role of the Big Five personality factors. Journal of Personality, 64(4), 775-813.

Ozer, D. J., \& Benet-Martinez, V. (2006). Personality and the prediction of consequential outcomes. Annual Review of Psychology, 578, 1-21.

Power, R. A., \& Pluess, M. (2015). Heritability estimates of the Big Five personality traits based on common genetic variants. Translational Psychiatry, 5(7), e604. https://doi.org/10.1038/tp.2015.96

Rentfrow, P. J., Gosling, S. D., \& Potter, J. (2008). A theory of the emergence, persistence, and expression of geographic variation in psychological characteristics. Perspectives on Psychological Science, 3(5), 339-369.

Rentfrow, P. J., Jokela, M., \& Lamb, M. E. (2015). Regional personality differences in Great Britain. PLoS ONE, 1O(3), 0122245. https://doi.org/10.1371/journal.pone.0122245

Roberts, B. W., Kuncel, N. R., Shiner, R., Caspi, A., \& Goldberg, L. R. (2007). The comparative validity of personality traits, socioeconomic status, and cognitive ability for predicting important life outcomes. Perspectives on Psychological Science, 2, 315-345.

Sampson, R. J., Raudenbush, S. W., \& Earls, F. (1997). Neighborhoods and violent crime: A multilevel study of collective efficacy. Science, 277(5328), 918-924.

Sharkey, P. (2008). The intergenerational transmission of context. American Journal of Sociology, 113(4), 931-969.

Stephens, M. (2013). Social housing in the United Kingdom. In J. Chen, M. Stephens, \& Y. Man (Eds.), The future of public housing (pp. 199-213). Springer.

Sykes, B., \& Musterd, S. (2010). Examining neighbourhood and school effects simultaneously. What does the Dutch evidence show? Urban Studies, 48(7), 1307-1331.

Vogel, M. \& van Ham, M. (2018). Unpacking the relationships between impulsivity, neighborhood disadvantage, and adolescent violence: An application of a neighborhood-based group decomposition. Journal of Youth and Adolescence, 47, 859-871. 
Wikström, P.-O.H., \& Sampson, R. J. (2003). Social mechanisms of community influences on crime and pathways in criminality. In B. B. Lahey, T. E. Moffitt, \& A. Caspi (Eds.), Causes of conduct disorder and juvenile delinquency (pp. 118-148). The Guilford Press.

Wilson, W. J. (1987). The truly disadvantaged. Chicago University Press.

Xue, Y., Leventhal, T., Brooks-Gunn, J., \& Earls, F. (2005). Neighborhood residence and mental health problems of 5-11-year-olds. Archives of General Psychiatry, 62, 554-563.

Yu, R., Nieuwenhuis, J., Meeus, W., Hooimeijer, P., Koot, H. M., \& Branje, S. (2016). Biological sensitivity to context: Cortisol awakening response moderates the effects of neighbourhood density on the development of adolescent externalizing problem behaviours. Biological Psychology, 120, 96-107.

Zimmerman, G. M. (2010). Impulsivity, offending, and the neighborhood: Investigating the person-context nexus. Journal of Quantitative Criminology, 26, 301-332.

Publisher's Note Springer Nature remains neutral with regard to jurisdictional claims in published maps and institutional affiliations. 